\title{
Phytoestrogens and the Intestinal Microbiome
}

\author{
L. KOLÁTOROVÁ ${ }^{1}$, O. LAPČÍK ${ }^{1,2}$, L. STÁRKA ${ }^{1}$ \\ ${ }^{1}$ Department of Steroids and Proteofactors, Institute of Endocrinology, Prague, Czech Republic, \\ ${ }^{2}$ Department of Chemistry of Natural Compounds, University of Chemistry and Technology, \\ Prague, Czech Republic
}

Received August 8, 2018

Accepted September 11, 2018

\section{Summary}

The microflora of the digestive tract is composed of a unique set of bacteria, yeasts, viruses and other microorganisms, generally known as the microbiome. The microbiome exhibits considerable inter-individual variability, with up to two-thirds of the microflora differing between individuals. Because of this, the variable intestinal microflora is responsible for many differences in metabolic, hormonal and immunological processes in humans and animals. Significant differences have been observed in the metabolism of phytoestrogens, naturally occurring substances that possess estrogenic or anti-estrogenic activity. These substances occur predominately in legumes, especially in soy and many soy products. Because of their effects, phytoestrogens are used as an alternative therapy for menopausal disorders and benign prostate hyperplasia. In connection with the worldwide expansion of soy products as part of healthy lifestyles including vegetarianism and veganism, phytoestrogens have become a regular part of everyday life. The activity of phytoestrogens is strongly dependent on the microbiome. Their metabolites have stronger estrogenic activity than the natural substances themselves, and because of the variability in microbiomes, there are large differences in the effects of phytoestrogens among individuals.

\section{Key words}

Phytoestrogens • Daidzein • Equol • Microbiota

\section{Corresponding author}

L. Kolatorova-Sosvorova, Department of Steroids and Proteofactors, Institute of Endocrinology, Narodni 8, 11694 Prague, Czech Republic. E-mail: Ikolatorova@endo.cz

\section{Introduction}

The term microflora generally refers to the living exogenic component of the gastrointestinal tract composed of bacteria, viruses, protozoans, and yeasts. Currently, the term microbiome is becoming more popular, encompassing the summary of all microbiotic genetic information.

There is a relatively long history of medical research on the influence of gastrointestinal microbiota on the metabolic functioning of the host organism. Veterinary medicine has dealt with this issue since the 1950s, while human medicine concentrated mainly on the microbial composition and activities in the oral-nasal cavities, and only later expanded interest to include the entire gastrointestinal tract.

The first important work that focused on metabolic processes in the intestines was a study on the microbial transformation of glucose to propionate in 1963 (Baldwin et al. 1963). A foundational study on the intestinal microbiota in the Czech Republic was the study on the colonization of the Escherichia coli bacteria in children, with the aim of reducing nosocomial infections (Lodinová et al. 1991). Today, the term microbiome, meaning the sum of microbiotic genetic information, has about 40,000 citations in biomedical databases.

This increase in research on the intestinal microbiota makes clear that the microbiome plays an important role in the health of the host. Knowledge of the metabolism and regulation mechanisms of humans must include information about the organism itself plus information about cells that are present but that do not 
come from the host's body. The mass of the intestinal microbiota ranges around $1-2 \mathrm{~kg}$ and current estimates put the number of organisms at $10^{13}$, with 10 times the number of genes than the human genome (Sender et al. 2017).

\section{The development of the microbiota}

The influence of the microbiota is determined partly by its composition, which is the result of factors both internal and external. The formation of the microbiome begins already during embryonic development, and a critical time is the period after birth, when the mother's milk plays an important protective role in the child. The microbiome is generally stabilized around the $2^{\text {nd }}$ to $3^{\text {rd }}$ year of life. Different people have greatly varied microbiotic compositions, but within an individual the composition is quite stable. However, changes do appear under the influence of various factors. Antibiotic treatment has a marked impact on the microbiota. Disruption of the intestinal equilibrium by antibiotics can lead to changes in up to $90 \%$ of analyzed metabolites such as bile acids, eicosanoids and steroid hormones. Subsequent disruption of metabolic pathways can be critically important to the host.

\section{The influence of the microbiota on metabolic processes}

The microbiota has a diverse composition including bacteria, protozoans, and viruses, and plays a key role in metabolizing compounds traversing the gastrointestinal tract, including food particles, medicines and toxins from the external environment, as well as compounds excreted into the gastrointestinal tract such as bile acids.

Bacteria, the most frequent members of the microbiota, can be taxonomically divided into the phyla Firmicultes, Bacteriodates, Protobacteria and Actinobacteria. Microbial fermentation breaks down dietary compounds and xenobiotics, and products can include compounds with hormonal character. On the other hand, hormones produced by humans are metabolically transformed by the microflora and can thus have different activity than the original hormone. The intestinal microbiota has even been called a new endocrine organ (Brown and Hazen 2015).

The microbiota produces a wide range of common enzymes, such as azoreductases, esterases, methylases, thiolases, lipases, nitroreductases, betaglucuronidases, sulfatases and beta-lysases, as well as specific hydroxylases, oxidoreductases and lysases important in steroid metabolism. Some metabolic pathways, for instance steroid hormones in the microbiota, are similar or the same as in the host, while others are specific and determined by the microbial composition. The capabilities of these microorganisms have been richly used in the pharmaceutical industry to produce compounds that are much more difficult to synthesize in other ways.

Microorganisms influence digestion, cleave complex saccharides, produce short-chain fatty acids, support detoxification, and synthesize various vitamins. They affect immunity and are part of the defense mechanism against pathogens. They regulate epithelial cell differentiation, and influence the development and physiology of various systems as well as the appearance and progression of some diseases. They have indirect effects on the central nervous system, influencing perceptions such as taste (Podzimek et al. 2018), mood, and behavior.

Just as the intestinal microbiota influence immunity, hormonal and nerve functions, so can the immune and endocrine system in the mucus of the gastrointestinal tract influence the microbial composition and regulate "intestinal health" (Šefčíková et al. 2010, Šefč́́ková and Bujňáková 2017). The host thus gains possible defenses against invasive pathogens by the production of antimicrobial peptides in the epithelial layer, such as defensin and cathelicidin. The microbiota and host influence each other in both directions.

\section{Phytoestrogens}

From a chemical point-of-view, phytoestrogens are a variable group of compounds. In contrast to estrogens themselves, they are not steroids, but rather products of several of the metabolic pathways of phenylpropanoids. This large group of compounds is common in multicellular plants, but do not occur in animals. Common characteristics of phytoestrogens include the presence of at least one benzene ring (usually two), a relatively stable and flat molecule, and two or three hydroxyl groups with distances similar to the distances between C3 and C17 in 17 $\beta$-estradiol (Mazur and Adlercreutz 2000). The molecular weights are also similar to those of natural estrogens. Active compounds of this type are thought to act through the estrogen 
receptors $\operatorname{ER} \beta$ and $\operatorname{ER} \alpha$ (Plišáková et al. 2010). Isoflavanoids, which are numerous in legumes, are the most important, followed by flavonoids, lignans, coumestans, ellagitannins, and stilbenes (Mazur and Adlercreutz 2000).

Direct estrogenic or anti-estrogenic activities are shown by only a fraction of the total number of known compounds in this group. Of practical significance are mainly genistein, daidzein and its metabolite $S$-equol, and to a degree also coumestrol - which while being actively estrogenic only occurs at very low concentrations. In addition it is also necessary to take into account those compounds that are transformed into estrogenically active isoflavones in the consuming organism, whether through their own metabolism or through the intestinal microflora. This mainly concerns various types of glycosides and methoxy derivatives (formononetin, biochanin). The intestinal microflora is almost the exclusive source of the production of the quite strongly active phytoestrogen $S$-equol.

\section{Molecular mechanisms of action}

Phytoestrogens are from one to four orders weaker ligands of the estrogen receptors (ER) than $17 \beta$-estradiol. Their intake, however, can reach tens to hundreds of milligrams per day, which enables them to reach effective concentrations in bodily fluids (tens of nanomoles to micromoles per liter). Isoflavones have a several times higher affinity for $\operatorname{ER} \beta$ than for ER $\alpha$, and thus act as partially selective modulators of ERs. This is actually an advantage, since the as-yet not completely understood causes of most estrogen-dependent malignancies are associated with activities of $E R \alpha$, while in contrast many physiological functions of estrogen may be modulated through ER $\beta$ (Hartman et al. 2009).

Individual phytoestrogens may also influence other signaling systems. Genistein inhibits tyrosine protein kinases, and therefore modulates the activities of hormones using the phosphorylation of tyrosine for intracellular signal transfers (e.g. insulin, IGF, EGF) and thus decreases the activities of several mitogens (Amanat et al. 2018). To fully take advantage of this effect, however, concentrations that are several orders of magnitude higher than that usually available through dietary intake are necessary. Genistein is also an inhibitor of topoisomerase II. Some phytoestrogens influence the biosynthesis pathways of steroid hormones. Enzymes that are inhibited include dehydrogenases of
17 $\beta$-hydroxysteroids, $3 \beta$-hydroxysteroids, and aromatase. This lowers the production of the most biologically active sex hormones, testosterone and estradiol. Genistein, biochanin A and $S$-equol are inhibitors of $5 \alpha$-reductases, and lower the local concentrations of dihydrotestosterone, the main androgen in the prostate. Phytoestrogens also influence the biological availability of sex hormones through the inhibition of sulfatase and sulfotransferase. Another important impact is the lowered activity of CYP24, an enzyme that plays a role in the degradation of calcitriol. Some isoflavones, genistein in particular, inactivate the transcription factor $N F-\kappa B$, which induces the expression of multiple genes participating in the inflammation process. Similar to other polyphenols, phytoestrogens are also antioxidants and free radical scavengers (Lapčík and Stárka 2007). There is also increased evidence that $S$-equol lowers insulin resistance (Horiuchu et al. 2017, Huang et al. 2017).

\section{Dietary sources}

The main source of isoflavonoid phytoestrogens in the diet are soy and soy products. Depending on the cultivar, level of ripeness, and method of preparation, the total amounts of daidzein and genistein (including glycosides) can reach several grams per kilogram of soy product. Glycitein and coumestrol are present in lower amounts. The levels available from other legumes that are commonly consumed (chickpeas, peas, shell beans, lentils, mungo beans, and alfalfa sprouts) are quite a bit lower, but still not negligible (Table 1).

Isoflavonoid concentrates used as dietary supplements are mostly produced from soy and red clover (Trifolium pratense). The isoflavonoid spectrum in clover differs from that of soy, with methoxy derivatives predominating (formononetin, biochanin A). In Asia, two members of the Pueraria genus - P. lobata and $P$. mirifica - are also used. P. lobate, or kudzu, is used for forage but also for human consumption. Kudzu is a rich source of daidzein and its C-glucoside puerarin, which is a strong inhibitor of alcohol dyhydrogenase. The roots of kudzu induce a disulfiram effect, and are used in traditional medicine as a treatment for alcoholism. A related species, $P$. mirifica, is common mostly in Thailand, where it is known as "white kwao krua". It plays a significant role in local ethnopharmacological traditions for reducing the symptoms of menopause (Cherdshewasart et al. 2007). 
Table 1. Phytoestrogen concentrations in selected foods.

\begin{tabular}{lcccc}
\hline Food & $\begin{array}{c}\text { Daidzein } \\
\mathbf{m g} / \mathbf{1 0 0 g}\end{array}$ & $\begin{array}{c}\text { Genistein } \\
\mathbf{m g} / \mathbf{1 0 0 g}\end{array}$ & $\begin{array}{c}\text { Formononetin } \\
\mathbf{m g} / \mathbf{1 0 0 g}\end{array}$ & $\begin{array}{c}\text { Biochanin A } \\
\mathbf{m g} / \mathbf{1 0 0 g}\end{array}$ \\
\hline Soy (beans) & $10-60$ & $26-100$ & 0.1 & 0.1 \\
Soy milk & $0.2-5$ & $0.3-6$ & - & - \\
Tofu & $5-15$ & $6-28$ & & \\
Soy sauce & 0.9 & 0.8 & 0 & 0 \\
Soy oil & 0 & 0 & 0.01 & 0.01 \\
Shell beans & 0.1 & 0.1 & 0.2 & 0.3 \\
Lentils & 0.2 & 0.3 & 22.3 & 20.4 \\
Red clover & 12.2 & 4 & & \\
\hline
\end{tabular}

Lignans are found in many plants. The most important source of precursors for enterolactone is flaxseed (Adlercreutz 2007, Calado et al. 2018). The estrogenically active flavonoid 8-prenylnaringenin and its precursors are part of a complex of phenol compounds found in beer (Štulíková et al. 2018). However, concentrations of prenylnaringenin in beer are low usually on the order of up to tens of micrograms per liter.

\section{The biological availability of phytoestrogens and the role of the intestinal microflora}

Isoflavones in plant material are present as aglycones or beta-glycosides. Both these forms (Fig. 1) are absorbed and enter the bloodstream as aglycones or as conjugates with glucuronic acid. Methylated isoflavonoids present in clover and other legumes are demethylated and undergo further transformations under the influence of intestinal bacteria.

In fact the metabolic activity of intestinal microflora plays a key role in the activities of phytoestrogens (Landete et al. 2015). Isoflavones, lignans, and other phenol compounds are mainly present in plants in the form of glycosides, and their hydroxyl groups, which are necessary for estrogenic activity, may be methylated. The first activation steps are therefore the cleaving of glycosidic bonds and demethylation. The conversion of daidzein, the important phytoestrogen in soy, is especially important. Daidzein is metabolized by the intestinal microbiota either to equol, which has higher

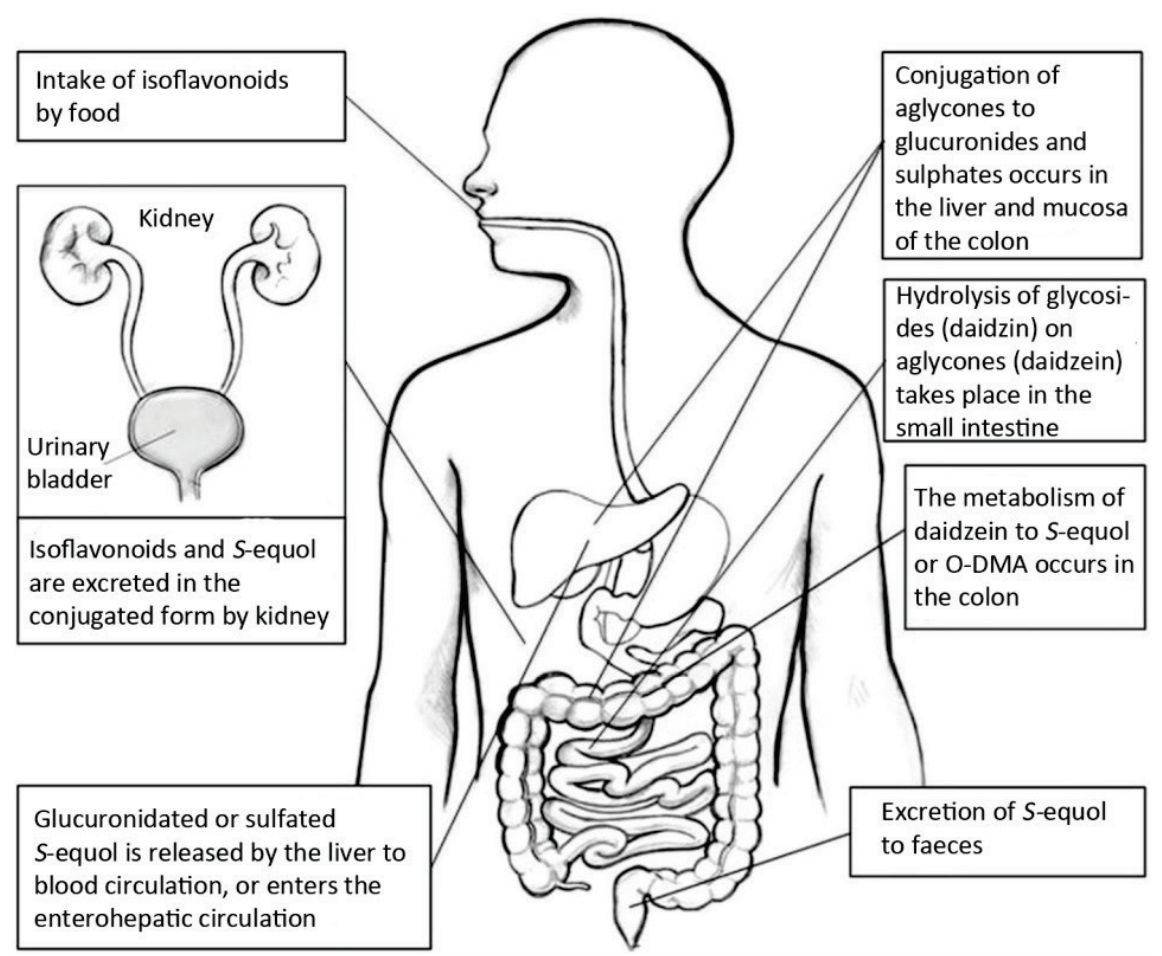

Fig. 1. The production and metabolism of $S$-equol in humans. Modified from Frankenfeld (2011). 
estrogenic activity, or to the relatively less active O-desmethylangolensin (O-DMA) (Fig. 2). Of both possible isomers of equol, the microflora produces only the $S$-isomer, and $R$-equol has only been produced synthetically. Because the bacterial flora is individually extremely variable, the production of intestinal estrogens is also variable. There are some people who can excrete equol after consuming soy products (about 30-50\% of the population), while others cannot and presumably have lower benefits from consuming phytoestrogens. In fact the production of $S$-equol is considered an indicator of the beneficial effects of soy on human health. Based on the ability of the intestinal microflora to metabolize phytoestrogens to more effective metabolites, some authors (Gaya et al. 2016, Miller et al. 2017) have divided individuals into three groups: 1) non-producers, 2) producers of O-DMA, and 3) producers of equol. According to one study, producers of equol are less common than producers of O-DMA (Gaya et al. 2016, Reverri et al. 2017), and the proportion of non-producers is estimated at about $40-60 \%$.

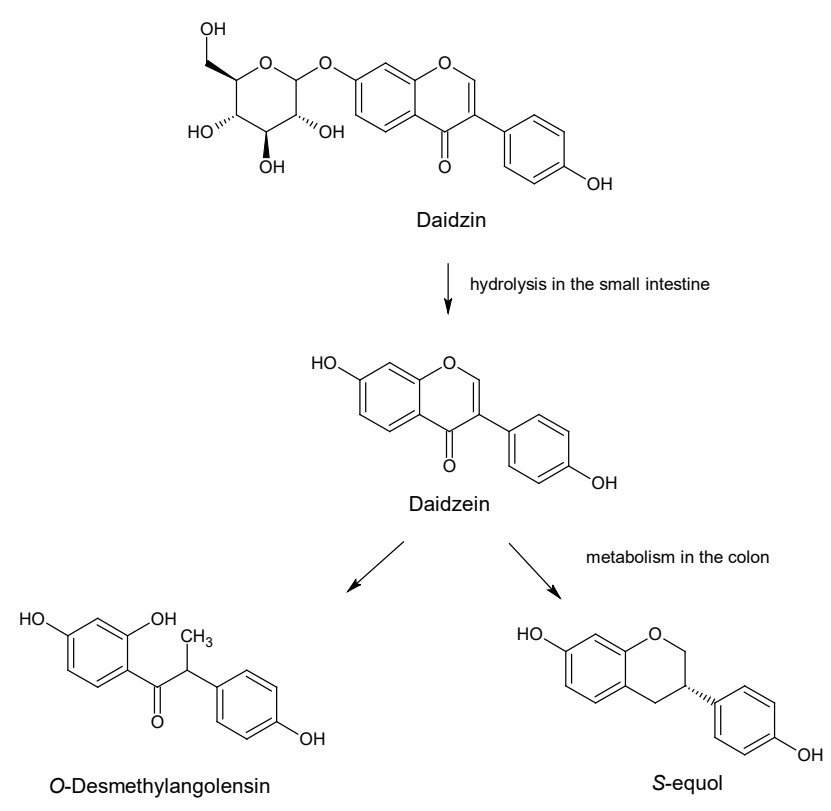

Fig. 2. The metabolism of the glycoside daidzein.

The bacteria responsible for the conversion of daidzein to equol were long unidentified. Tests of probiotic strains of the Lactobacillus and Bifidobacterium genera proved negative. A mixed culture able to metabolize daidzein to $S$-equol was prepared from human fecal microflora (Decroos et al. 2005), and an as-yet nonclassified gram-positive anaerobic rod with the same characteristics was found in the intestines of rats (Minamida 2006). In humans, bacteria responsible for this transformation were later identified as Adlercreutzia equolifaciens, Eggerthella spp. and Slackia isoflavoniconvertens, while Asaccharobacter celatus and Enterorhabdus musicola were identified in the microflora of mice (Maruo et al. 2008, Tamura et al. 2016).

Similarly, both enterolacton and enterodiol, active phytoestrogens of the lignan type, arise from the conversion by the microflora of plant precursors. The estrogenic lignan enterolacton comes from several plant precursors (e.g. matairesinol, secolariciresinol), through the activities of Eggerthella bacteria in the intestine.

The conversion of isoxanthohumol, which is present in hops and in beer an order of magnitude higher than active prenylnaringenin, to estrogenic active 8-prenylnaringenin occurs through the activities of Eubacterium limosum with an efficiency of up to $36 \%$, and which has been observed in one-third of intestinal microflora samples (Possemiers et al. 2006). Selected Eubacterium limosum strains have been shown to convert up to $90 \%$ of 8-prenylnaringenin to ixoxanthohumol. This gram-positive rod also demethylates some isoflavonoids. Antibiotic treatment reduces the conversion of daidzein to $S$-equol and other metabolites, and can negatively impact the effectivity of phytoestrogen supplements (Atkison et al. 2005). The effectivity of plant-base supplements is affected by not only the composition and concentration of phytoestrogens, but also the further metabolic fate of those compounds present. The metabolic processing of supplemental phytoestrogens is the result of teamwork between the microbiota and their host.

The microbial transformations of stilbene (Koyani and Vazquez-Duhalt 2018) and coumestan are still little studied. Isoflavins, ellagitannins, and lignans are metabolized by the intestinal microbiota to equol, urolithin, and enterolignan, which are more biological available and have higher estrogenic/anti-estrogenic and antioxidant activities than their precursors. These microbial products also have anti-inflammatory and anti-proliferative effects, and induce the process of increased apoptosis. These effects have protective functions against several chronic diseases, such as cardiovascular disease, carcinomas, osteoporosis, and menopausal symptoms. The effectiveness of dietary phytoestrogens is largely determined by the individual intestinal microbial composition (Landete et al. 2015).

Since they are a significant part of humulone 
coming from the resin of hops, beer contains prenylflavonoids, including 8-prenylnaringenin, one of the most effective phytoestrogens. Since the concentrations of 8-prenylnaringenin in beer tend to be low, the effects of phytoestrogens on health coming from a minor consumption of beer are considered to be negligible. However, the intestinal microbiota is able to transform up to $4 \mathrm{mg} / \mathrm{l}$ of isoxanthohumulone to 8-prenylnaringenin, and this metabolic conversion increases the hosts exposure to 8-prenylnaringenin by up to 10 times. This activation takes place in the distal part of the large intestines (Possemiers et al. 2005).

The pathways of metabolic conversions of phytoestrogens also depend on the hormonal status of the host. The influence of ovariectomies on the production of genistein metabolites has been studied in female rats, and it was found that there was a difference in metabolic composition arising from the microbiota between falselyoperated and animals with those with true ovareictomies (Lee et al. 2017). In humans, children up to three years old have a lower microbial ability to metabolize isoflavones, ellagitannins, and lignans. The products of their microbiota lack 5-hydroxy-equol and enterodiol, and the production of urolithin and enterolactone are reduced (Gaya et al. 2018). Similarly to the microbiota, which influences the digestion of food in the gastrointestinal tract, dietary composition is another main factor influencing the intestinal microbial ecosystem (Rist et al. 2014, Péres-López et al. 2106, Miynt et al. 2017).

\section{Treatments with phytoestrogen supplements}

Phytoestrogens have mainly been studied as possible alternatives to hormonal replacement therapy (HRT) in menopause. The successful use of phytoestrogens as an alternative to HRT should replace most of the activities of estrogens, but on the other hand should not increase the risk of thromboembolic disease or especially breast cancer (Stárka and Lapčík 2006).

Phytoestrogen-containing products have found use as dietary supplements aimed at lessening the sideeffects of perimenopause and during menopause itself, but are unable to completely overcome the estrogenic deficit (Sosvorová et al. 2011). In men, they have been used in urology to reduce difficulties with the lower urinary tract, particularly in cases due to benign prostate hyperplasia.
Soy products, though not all, are a rich natural source of isoflavonoids. Dietary supplements are mostly derived from soy extracts and red clover. Cimicifuga racemose is widely sold commercially, even though its active compounds are not well-known. In various countries phytoestrogens are classified variously as medicines or dietary supplements, and patients often obtain them without a prescription and use them without medical supervision. It has repeatedly been demonstrated that not all products actually contain the stated amounts of active ingredients. Despite these downsides, phytoestrogens are an important instrument in the treatment of decreased estrogen secretion (Lapčík and Sosvorová 2011).

An additional problem is the dependence on the effectiveness of phytoestrogen products on the activities of the intestinal microflora. This is also why many effects vary between individuals using similar products. Phytoestrogen products are quite difficult to standardize, the active ingredients occur in different proportions, and plant extracts also contain other biologically active compounds. Tests in vitro often differ from the actual biological effects due to the individual differences in biological availability, microbial transformations, and uniqueness of each patient.

\section{Conclusion}

The microbiota significantly affects several metabolic transformations of various phytoestrogens. Depending on the microbial composition, less-effective precursors may or not be transformed into active metabolites, such as in the case of daidzein $-S$-equol. For this reason, women using phytoestrogen products for symptoms of menopause and men treated for lower urinary tract difficulties can be either producers or nonproducers, with treatment success more likely in the first group.

\section{Conflict of Interest}

There is no conflict of interest.

\section{Acknowledgements}

This review was supported by a grant from the Czech Ministry of Health, RVO (Institute of Endocrinology EU 00023761). 


\section{References}

ADLERCREUTZ H: Lignans and human health. Critical Rev Clin Lab Sci 44: 483-525, 2007.

AMANAT S, EFTEKHARI MH, FARAROUEI M, LANKARANI KB, MASSOUMI SJ: Genistein supplementation improves insulin resistance and inflammatory state in non-alcoholic fatty liver patients: a randomized, controlled trial. Clin Nutr 37: 1210-1215, 2018.

ATKINSON C, FRANKENFELD CL, LAMPE JW: Gut bacterial metabolism of the soy isoflavone daidzein: exploring the relevance to human health. Exp Biol Med (Maywood) 230: 155-170, 2005.

BALDWIN RL, WOOD WA, EMERY RS: Conversion of glucose-C14 to propionate by the rumen microbiota. J Bacteriol 85: 1346-1249, 1963.

BROWN JM, HAZEN SL: The gut microbial endocrine organ: bacterially derived signals driving cardiometabolic diseases. Ann Rev Med 66: 343-359, 2015.

CALADO A, NEVES PM, SANTOS T, RAVASCO P: The effect of flaxseed in breast cancer: a literature review. Front Nutr 5: 4, 2018.

CHERDSHEWASART W, SUBTANG S, DAHLAN W: Major isoflavonoid contents of the phytoestrogen rich-herb Pueraria mirifica in comparison with Pueraria lobata. J Pharmaceut Biomed Analysis 43: 428-434, 2007.

DECROOS K, VANHEMMENS S, CATTOIR S, BOON N, VERSTRAETE W: Isolation and characterisation of an equol-producing mixed microbial culture from a human faecal sample and its activity under gastrointestinal conditions. Arch Microbiol 183: 45-55, 2005.

FRANKENFELD CL: O-desmethylangolensin: the importance of equol's lesser known cousin to human health. $A d v$ Nutr 2: 317-324, 2011.

GAYA P, MEDINA M, SÁNCHEZ-JIMÉNEZ A, LANDETE JM: Phytoestrogen metabolism by adult human gut microbiota. Molecules 21: E1034, 2016.

GAYA P, SÁNCHEZ-JIMÉNEZ A, PEIROTÉN Á, MEDINA M, LANDETE JM: Incomplete metabolism of phytoestrogens by gut microbiota from children under the age of three. Int J Food Sci Nutr 69: 334-343, 2018.

HARTMAN J, STRÖM A, GUSTAFSSON JA: Estrogen receptor beta in breast cancer - diagnostic and therapeutic implications. Steroids 74: 635-641, 2009.

HORIUCHI H, USAMI A, SHIRAI R, HARADA N, IKUSHIRO S, SAKAKI T, NAKANO Y, INUI H, YAMAJI R: S-equol activates cAMP signaling at the plasma membrane of INS-1 pancreatic $\beta$-cells and protects against streptozotocin-induced hyperglycemia by increasing $\beta$-cell function in male mice. $J$ Nutr 147: 1631-1639, 2017.

HUANG G, XU J, LEFEVER DE, GLENN TC, NAGY T, GUO TL: Genistein prevention of hyperglycemia and improvement of glucose tolerance in adult non-obese diabetic mice are associated with alterations of gut microbiome and immune homeostasis. Toxicol Appl Pharmacol 332: 138-148, 2017.

KOYANI RD, VAZQUEZ-DUHALT R: Enzymatic activation of the emerging drug resveratrol. Appl Biochem Biotechnol 185: 248-256, 2018.

LANDETE JM, ARQUÉS J, MEDINA M, GAYA P, DE LAS RIVAS B, MUÑOZ R: Bioactivation of phytoestrogens: Intestinal bacteria and Health. Critical Rev Food Sci Nutr 56: 1826-1843, 2016.

LANDETE JM, GAYA P, RODRÍGUEZ E, LANGA S, PEIROTÉN Á, MEDINA M, ARQUÉS JL: Probiotic bacteria for healthier aging: immunomodulation and metabolism of phytoestrogens. Biomed Res Int 2017: 5939818, 2017.

LAPČÍK O, SOSVOROVÁ L: Phytoestrogens and their use in menopause (in Czech). Int Med Prax 13: 55-59, 2011.

LAPČÍK O, STÁRKA L: Phytoestrogens (in Czech). In: Pokroky v endokrinologii. STÁRKA L (ed.), MaxdorfJessenius, Praha, 2007, pp 201-212.

LEE DH, KIM MJ, SONG EJ, KIM JH, AHN J, NAM YD, JANG YJ, HA TY, JUNG CH: Nutrikinetic study of genistein metabolites in ovariectomized mice. PLoS One 12: e0186320, 2017.

LODINOVÁ-ZÁDNÍKOVÁ R, TLASKALOVÁ H, BARTÁKOVÁ Z: The antibody response in infants after colonization of the intestine with E. coli O83. Artificial colonization used as a prevention against nosocomial infections. Adv Exp Med Biol 310: 329-335, 1991. 
MARUO T, SAKAMOTO M, ITO C, TODA T, BENNO Y: Adlercreutzia equolifaciens gen. nov., sp. nov., an equolproducing bacterium isolated from human faeces, and emended description of the genus Eggerthella. Int J Syst Evol Microbiol 58: 1221-1227, 2008.

MAZUR W, ADLERCREUTZ H: Overview of naturally occurring endocrine-active substances in the human diet in relation to human health. Nutrition 16: 654-658, 2000.

MILLER LM, LAMPE JW, NEWTON KM, GUNDERSEN G, FULLER S, REED SD, FRANKENFELD CL: Being overweight or obese is associated with harboring a gut microbial community not capable of metabolizing the soy isoflavone daidzein to O-desmethylangolensin in peri- and post-menopausal women. Maturitas 99: 37-42, 2017.

MINAMIDA K, TANAKA M, ABE A, SONE T, TOMITA F, HARA H, ASANO K: Production of equol from daidzein by gram-positive rod-shaped bacterium isolated from rat intestine. $J$ Biosci Bioeng 102: 247-250, 2006.

MYINT H, IWAHASHI Y, KOIKE S, KOBAYASHI Y: Effect of soybean husk supplementation on the fecal fermentation metabolites and microbiota of dogs. Anim Sci J 88: 1730-1736, 2017.

PÉREZ-LÓPEZ E, CELA D, COSTABILE A, MATEOS-APARICIO I, RUPÉREZ P: In vitro fermentability and prebiotic potential of soyabean Okara by human faecal microbiota. Br J Nutr 116: 1116-1124, 2016.

PILŠÁKOVÁ L, RIEČANSKÝ I, JAGLA F: The physiological actions of isoflavone phytoestrogens. Physiol Res 59: 651-664, 2010.

PODZIMEK Š, DUŠKOVÁ M, BROUKAL Z, RÁCZ B, STÁRKA L, DUŠKOVÁ J: The evolution of taste and perinatal programming of taste preferences. Physiol Res 67 (Suppl 3): S421-S429, 2018.

POSSEMIERS S, HEYRICK A, ROBBENS V, DE KEUKELEIRE D, VERSTRAETE W: Activation of proestrogens from hops (Humulus lupulus L.) by intestinal microbiota; conversion of isoxanthohumol into 8-prenylnaringenin. J Agric Food Chem 53: 6281-6288, 2005.

REVERRI EJ, SLUPSKY CM, MISHCHUK DO, STEINBERG FM: Metabolomics reveals differences between three daidzein metabolizing phenotypes in adults with cardiometabolic risk factors. Mol Nutr Food Res 61: 1500815, 2017.

RIST VT, WEISS E, SAUER N, MOSENTHIN R, EKLUND M: Effect of dietary protein supply originating from soybean meal or casein on the intestinal microbiota of piglets. Anaerobe 25: 72-79, 2014.

SENDER R, FUCHS S, MILO R: Revised estimates for the number of human and bacteria cells in the body. PLoS Biol 14: e1002533, 2016.

SOSVOROVÁ L, BIČÍKOVÁ M, LAPČÍK O: Efficacy and safety of phytoestrogen products (in Czech). DMEV 14: 141-144, 2011.

STÁRKA L, LAPČÍK O: Replacement of hormonal replacement therapy? (in Czech) DMEV 9 (Suppl 1): 39-45, 2006.

ŠEFČÍKOVÁ Z, BUJŇÁKOVÁ D: Effect of pre- and post-weaning high-fat dietary manipulation on intestinal microflora and alkaline phosphatase activity in male rats. Physiol Res 66: 677-685, 2017.

ŠEFČÍKOVÁ Z, BUJŇÁKOVÁ D, RAČEK L, KMET V, MOZEŠ Š: Developmental changes in gut microbiota and enzyme activity predict obesity risk in rats arising from reduced nests. Physiol Res 60: 337-346, 2011.

ŠTULIKOVÁ K, KARABIN M, NEŠPOR J, DOSTÁLEK P: Therapeutic perspectives of 8-prenylnaringenin, a potent phytoestrogen from hops. Molecules 23: 660, 2018.

TAMURA M, HORI S, NAKAGAWA H, YAMAUCHI S, SUGAHARA T: Effects of an equol-producing bacterium isolated from human faeces on isoflavone and lignan metabolism in mice. J Sci Food Agric 96: 3126-3132, 2016. 